๑) Open Access Full Text Article

\title{
Milnacipran: recent findings in depression
}

\author{
Guest editors: Stuart Montgomery (London, UK) and Mike Briley (Castres, France)
}

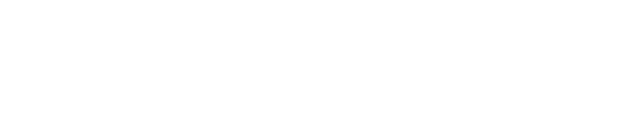

\section{EDITORIAL FOREWORD}

Milnacipran: recent findings in depression

Stuart Montgomery (London, UK) and Mike Briley (Castres, France)

\section{REVIEWS}

Suicidality: risk factors and the effects of antidepressants. The example of parallel reduction of suicidality and other depressive symptoms during treatment with the SNRI, milnacipran

Philippe Courtet (Montpellier, France)

Treatment of patients with comorbid depression and diabetes with metformin and milnacipran

Peter Hofmann (Graz, Austria)

Antidepressant therapy with milnacipran and venlafaxine

Lucilla Mansuy (Toulouse, France)

Milnacipran: a unique antidepressant?

Siegfried Kasper and Gerald Pail (Vienna, Austria)

This supplement is based on a symposium that took place at the 9th International Forum on Mood and Anxiety in Monte Carlo in November 2009 and is supported by an unconditional education grant from Pierre Fabre Médicament. 